Products and Services In Practice is provided to readers using text and images from the manufacturer, supplier or distributor and does not imply endorsement by $B D J$ In Practice. Normal and prudent research should be exercised before purchase or use of any product mentioned.

Please send product and services news through to David Westgarth, BDJ In Practice via: David.Westgarth@bda.org

\section{Cater to tech-savvy teens}

Research shows that young people who use computers excessively are more likely to neglect their oral health. Get teenagers motivated about oral hygiene by recommending the Hydrosonic Pro toothbrush from Curaprox.

Delivering up to 42,000 motions per minute, this toothbrush combines a built-in timer with one-button operation for ultimate usability. It comes complete with three brush heads boasting ultra-soft CUREN filaments and CURACURVE ergonomics to facilitate gentle but effective cleaning. A powerful battery also ensures the Hydrosonic Pro can last for up to two weeks on a full charge to accommodate twice-daily toothbrushing.

For more information call 01480 862084, email info@curaprox.co.uk or visit www.curaprox.co.uk.

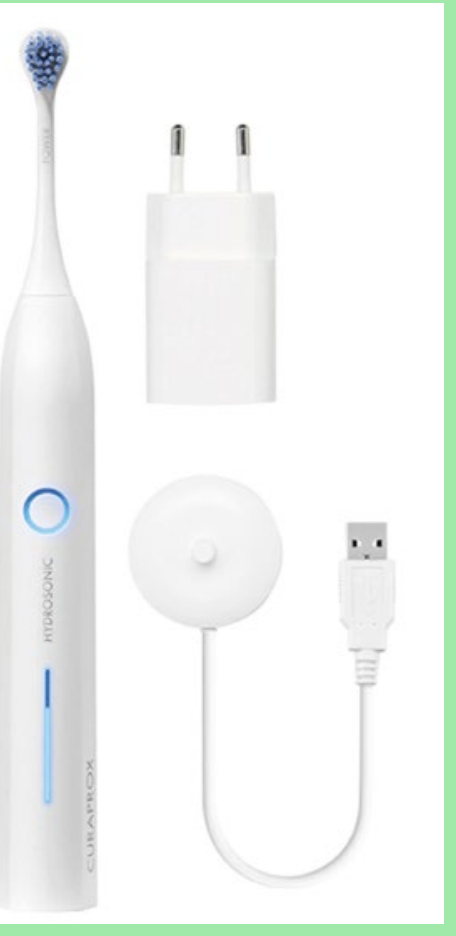

\title{
A sportsperson's best friend
}

Many sports carry the risk of dental trauma - so how do you keep your patients protected?

Shield them when it counts by offering Saber Protect mouth guards from CosTech Dental Laboratory.

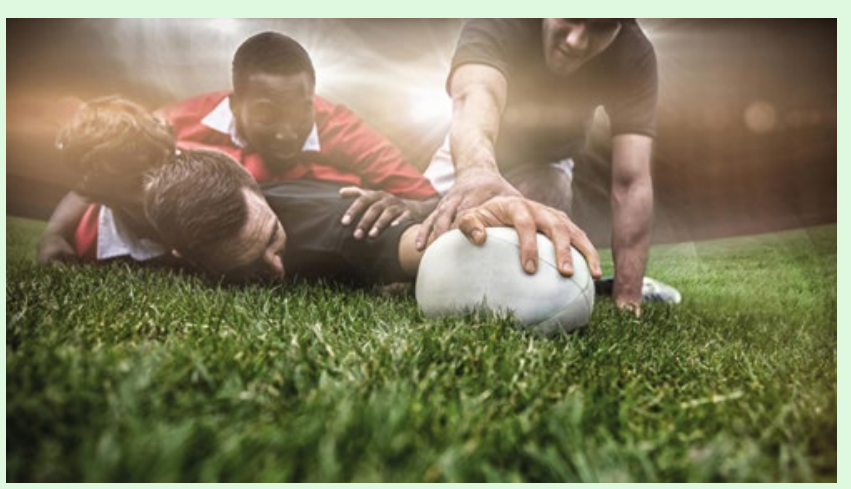

Completely custom-made to every individual, these innovative mouth guards offer extra levels of protection depending on which sport the person needs them for. By varying the thickness and levels of shock absorption, CosTech can craft these mouth guards to offer truly superior protection for sportspeople of all levels.

Keep them protected on the field, court, slopes and beyond by contacting CosTech Dental laboratory on 01474 320076 or by visiting www.costech.co.uk.

\section{The only composite you'll ever need}

With a history of award-winning innovation, COLTENE is on the cutting edge of composites

Combining excellent aesthetic results EverGlow is an advanced but intuitive composite.

Its abrasion resistance and high compressive strength make it a first choice as a posterior composite filling, while its sophisticated composition ensures a smooth, shiny surface that facilitates fabulous aesthetics in the anterior zone.

To top it off, BRILLIANT

EverGlow offers a Duo Shade system, which makes shade management extremely simple. Alongside a universal with remarkable ease of use BRILLIANT set of shades, even the most difficult to match teeth can be approximated with five additional shades available for rare variations.

To find out more visit www.coltene.com, email info.uk@coltene.com or call 01444 235486.

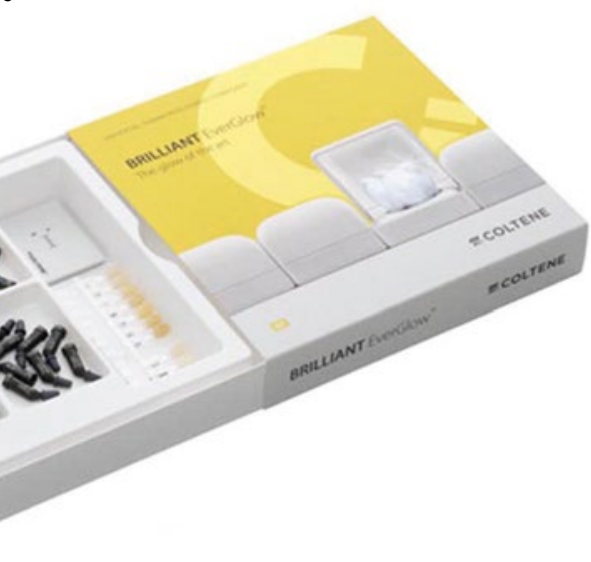

